\title{
Long-Term Oral Bisphosphonate Compliance Focusing on Switching of Prescription Pattern
}

This article was published in the following Dove Press journal:

Patient Preference and Adherence

\author{
Kyung Rae Ko' \\ Sangcheol Lee $\mathbb{D}^{2}$ \\ Seo Yoon $\mathrm{Oh}^{3}$ \\ Ki-duk Kim ${ }^{4}$ \\ Sin Hyung Park iD ${ }^{4 *}$ \\ Soonchul Lee iD ${ }^{2 *}$ \\ 'Department of Orthopaedic Surgery, \\ Samsung Medical Center, Sungkyunkwan \\ University School of Medicine, Seoul, \\ Republic of Korea; ${ }^{2}$ Department of \\ Orthopaedic Surgery, CHA Bundang \\ Medical Center, CHA University, \\ Seongnam-si, Gyeonggi-do, Republic of \\ Korea; ${ }^{3}$ University of California, Berkeley, \\ CA 94720, USA; ${ }^{4}$ Department of \\ Orthopaedic Surgery, Bucheon Hospital, \\ Soonchunhyang University School of \\ Medicine, Bucheon-si, Gyeonggi-do, \\ Republic of Korea \\ *These authors contributed equally to \\ this work
}

Background: Factors determining bisphosphonate compliance are not fully understood. We examined fluctuations in oral bisphosphonate dosing intervals to gauge therapeutic compliance in patients with osteoporosis.

Materials and Methods: Hospital data accruing between 2010 and 2017 were accessed to retrospectively study patients $\geq 50$ years old $(\mathrm{N}=1873$ ), each prescribed bisphosphonate at initial diagnosis of osteoporosis. The medication possession ratio (MPR), calculated as total days supplied divided by length of follow-up, served to measure therapeutic compliance. We compared MPRs of various prescription patterns (daily, weekly, monthly, and switch [ie, $\geq 1$ change in pattern] groups). We also analyzed the impact of age, sex, fracture history, surgical history, and comorbidities. Multiple regression analysis was ultimately performed, using MPR as a dependent variable.

Results: In our cohort (mean follow-up $=5.7 \pm 2.4$ years), once weekly dosing was the most common prescription pattern $(1223 / 1873,65.3 \%)$, as opposed to monthly $(366 / 1873,19.5 \%)$ or daily (164/1873, 8.8\%) dosing. A total of 120 patients $(6.4 \%)$ comprising the switch group changed dosing patterns during the study period. MPR was significantly higher in the switch group (32.8 \pm 22.7 ) than in the other three groups (daily, 21.9 \pm 25.9 ; weekly, $22.7 \pm 27.3$; monthly, 23.2 \pm 27.7$)$. In multiple regression analysis, younger age $(P<0.001)$, female sex $(P=0.004)$, and switching of prescription pattern (decrease or increase frequency) were factors significantly associated with higher MPR, signaling better compliance.

Conclusion: Better bisphosphonate compliance was associated with physician-modified dosing patterns. We therefore recommend adjustments of prescription intervals in poorly compliant patients requiring long-term treatment.

Keywords: bisphosphonate, compliance, medication possession ratio, MPR

\section{Introduction}

Osteoporosis is a chronic, systemic disease of bone metabolism, resulting in bony deterioration, diminished bone density and strength, and heightened risk of bone fracture. ${ }^{1,2}$ The goals of therapy are minimization of bone loss, mineral density replenishment, and improved microarchitectural integrity, thus mitigating the potential for skeletal fractures. ${ }^{3,4}$ The Korea Health and Nutrition Examination Survey database indicates a prevalence of $38.0 \%$ in women $>50$ years old, compared with $7.3 \%$ in male counterparts. ${ }^{5}$ In $2012,588,377$ (1165 per 100,000) National Health Insurance registrants were newly diagnosed with osteoporosis. ${ }^{6}$

Given the chronicity and required long-treatment of this disease, drug compliance is essential for therapeutic success. ${ }^{7-12}$ Compliant patients experience fewer fractures overall, whether vertebral, non-vertebral, or hip fractures. ${ }^{13,14}$ Unfortunately, related

Sin Hyung Park

Department of Orthopaedic Surgery, Bucheon Hospital, Soonchunhyang University School of Medicine, I 70

Jomaru-Ro, Bucheon-si, Gyeonggi-do, Republic of Korea

Tel +82 32-62I-5II4

Fax +82 32-708-3578

Email Sh0803@schmc.ac.kr 
therapies have met with poor compliance in recently conducted clinical studies, with first-year treatment lapses in two of every five patients. ${ }^{7,-15-17}$ The various factors involved in treatment compliance are not fully understood, although dosing requirements, medical insurance impediments, medication costs, side-effects of medications, and patient-physician rapport are implicated. ${ }^{18,19}$

A number of agents, including antiresorptive agents (such as bisphosphonates), estrogen or selective estrogen receptor modulators, parathyroid hormone or its analog, and monoclonal antibodies, have been developed and readily commercialized for treatment of osteoporosis. ${ }^{20}$ Oral bisphosphonates are more often prescribed to women with clinically evident postmenopausal osteoporosis or particular susceptibility to osteoporotic fractures to reduce their risk. ${ }^{21,22}$ In the past, manufacturers have suggested higher, less frequent bisphosphonate dosing (weekly, monthly, or quarterly) to encourage compliance, lessen chances of adverse effects, and minimize user inconvenience without sacrificing efficacy. These alternate dosing schedules have now outpaced daily dosing. According to some sources, compliance may be enhanced through weekly (vs. daily) bisphosphonate regimens, ${ }^{23-25}$ whereas weekly and monthly dosing comparisons yield mixed results. ${ }^{25,26}$ Furthermore, we have found little information on dosing shifts or their consequences in this setting. ${ }^{27}$ The impact of bisphosphonate prescription patterns on patient compliance is thus open to debate.

Under these circumstances, we endeavored to assess compliance in patients prescribed bisphosphonates for osteoporosis, focusing on dosing patterns. Comparable research available to date is largely confined to 1-year periods, essentially ignoring long-term trends. ${ }^{17,-28-30}$ Our data were collected from medical records and telephone interviews, spanning periods of up to 9 years. We hypothesized that dosing patterns would affect compliance in patients prescribed bisphosphonates. We also hypothesized that switching of prescription patterns would improve compliance by minimizing its declines over time.

\section{Materials and Methods}

\section{Study Design and Source of Data}

This retrospective, observational cohort study was undertaken with the approval of the institutional review board at CHA University (No. 2018-10-024-004), using hospital database parameters to evaluate therapeutic compliance in newly prescribed users of oral bisphosphonates. The informed consent was waived because the analysis used anonymous clinical data with the retrospective design. Data were retrieved from orders communicated and electronic medical record systems in which diagnostic and prescription claims data for each patient are archived. To generate more precise patient profiles and characteristics, all patients with insufficient information were indirectly contacted and interviewed via telephone conversations after initially assessing the data.

\section{Selection of Study Subjects}

Study candidates were older adults ( $\geq 50$ years) for whom anti-osteoporotic agents were prescribed at initial diagnosis of osteoporosis within the period of study (January 2010 to December 2017). The International Statistical Classification of Diseases and Related Health Problems, 10th revision (ICD-10) was applied, restricting candidates to the following diagnostic codes: M80, Osteoporosis with pathological fracture; M81, Osteoporosis without pathological fracture; or M82, Osteoporosis in diseases classified elsewhere.

Exclusion criteria were as follows: (1) prior history of prescribed anti-osteoporotic agent $(n=1113)$; (2) use of nonbisphosphonate anti-osteoporotic medication during the study period ( $\mathrm{n}=1180$ ); and (3) parenteral (IV) bisphosphonate administration $(n=320)$. Ultimately, 1873 patients qualified for study. A schematic of the selection process is shown in Figure 1.

\section{Measurement of Compliance}

Compliance was measured by using a medication possession ratio (MPR). In this study, it was defined as the proportion of medication supply obtained in relation to medication supply expected during the follow-up period. ${ }^{31}$ All study subjects were newly diagnosed with osteoporosis and followed-up for its treatment. No subjects discontinued their prescriptions due to drug holiday. Therefore, we calculated MPR as the proportion of total daily supply divided by length of follow-up. For example, three packets (four pills each) of weekly bisphosphonate prescribed in the course of 1 year yield the following MPR: $[(3$ packets $\times 4$ pills $\times 7$ days $) / 365$ days $] \times 100=23(\%)$.

All bisphosphonates dispensed at our institution during the study period were closely monitored. In purchasers of bisphosphonate, prescription patterns (ie, dosing intervals from index date to study completion) were grouped as daily, weekly, monthly, and switch (switched $\geq 1$ time during study period). 


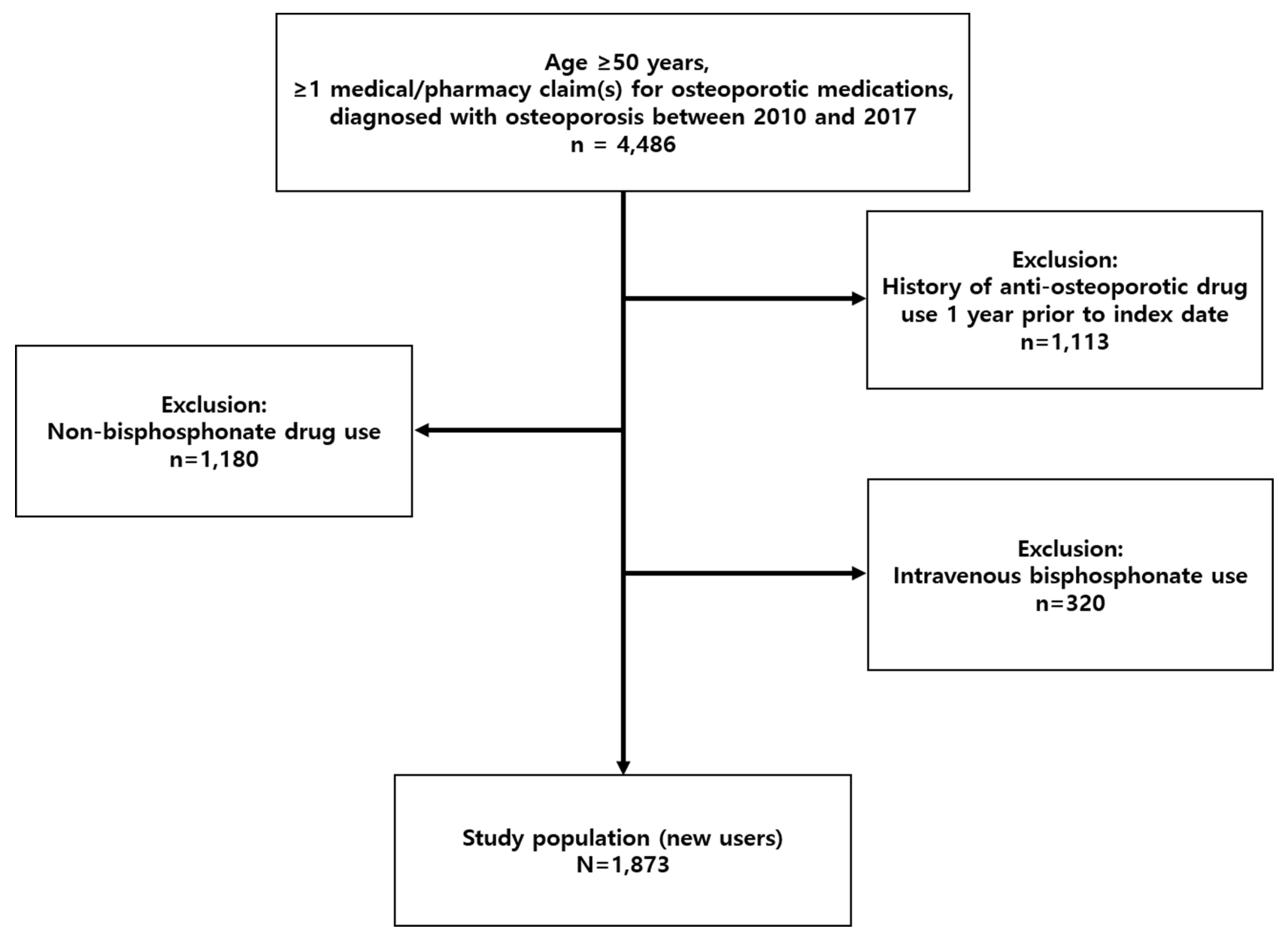

Figure I Schematic of process for subject selection.

Previous osteoporotic fractures of spine, hip, distal radius, or proximal humerus were tracked, along with primary diagnosis, and coded as follows: M80, Osteoporosis with pathological fracture; S72.0, Fracture of neck of femur; S72.1, Pertrochanteric fracture; S22.0, Fracture of the thoracic vertebra; S22.1, Multiple fractures of the thoracic spine; S32.0, Fracture of lumbar spine and pelvis; M48.4, Fatigue fracture of vertebra; M48.5, Collapsed vertebra, NEC; S52.5, Fracture of lower end of radius; S52.6, Fracture of lower end of both ulna and radius; S42.2, Fracture of upper end of humerus; or S42.3, Fracture of shaft of humerus. Fracture histories were confirmed through chart reviews, and surgical procedures for osteoporotic fractures were investigated.

\section{Statistical Analyses}

All numerical values were expressed as mean \pm standard deviation. To compare MPRs and follow-up periods by subgroup, ANOVA with LSD as post hoc test, independent $t$-test, or paired $t$-test was used. Multiple regression analysis was invoked to ascertain significant variables impacting MPR. All computations entailed standard software (SPSS v23 for Windows; IBM Corp, Armonk, NY, USA), setting significance at $P<0.05$.

\section{Results}

Demographics and clinical characteristics of the study population are summarized in Table 1. The most common pattern among prescriptions issued was weekly dosing $(1223 / 1873,65.3 \%)$, followed by monthly $(366 / 1873$, $19.5 \%)$ and daily $(164 / 1873,8.8 \%)$. These 1753 patients maintained their initial regimen. The remaining 120 patients $(6.4 \%)$ switched dosing patterns during the study period. Among the 120 patients, the initial regimen was weekly dosing (77/120, 75.8\%), followed by monthly (29/ $120,24.2 \%)$ and daily (14/120, 11.7\%). Dosing frequency was decreased in 77 patients at $2.3 \pm 1.4$ years. On the other hand, it was increased in 43 patients at $3.2 \pm 1.8$ years. 
Table I Demographics and Clinical Characteristics of Study Subjects

\begin{tabular}{|c|c|c|c|c|c|c|}
\hline & & Total N (\%) & Daily & Weekly & Monthly & Switch \\
\hline & & $1873(100)$ & $164(8.8)$ & $1223(65.3)$ & $366(19.5)$ & $120(6.4)$ \\
\hline Age, years & $\begin{array}{l}50-59 \\
60-69 \\
70-79 \\
\geq 80\end{array}$ & $\begin{array}{l}495(26.4) \\
607(32.4) \\
555(29.6) \\
216(11.5)\end{array}$ & $\begin{array}{l}35(21.3) \\
40(24.4) \\
63(38.4) \\
26(15.9)\end{array}$ & $\begin{array}{l}368(30.1) \\
413(33.8) \\
324(26.5) \\
118(9.6)\end{array}$ & $\begin{array}{l}73(19.9) \\
103(28.1) \\
128(35.0) \\
62(16.9)\end{array}$ & $\begin{array}{l}19(15.8) \\
51(42.5) \\
40(33.3) \\
10(8.3)\end{array}$ \\
\hline Sex & $\begin{array}{l}\text { Male } \\
\text { Female }\end{array}$ & $\begin{array}{l}324(17.3) \\
1549(82.7)\end{array}$ & $\begin{array}{l}18(11.0) \\
146(89.0)\end{array}$ & $\begin{array}{l}259(2 \mathrm{I} .2) \\
964(78.8)\end{array}$ & $\begin{array}{l}31(8.5) \\
335(91.5)\end{array}$ & $\begin{array}{l}16(13.3) \\
104(86.7)\end{array}$ \\
\hline $\begin{array}{l}\text { Fracture history } \\
\text { Surgical history } \\
\text { HTN } \\
\text { DM }\end{array}$ & $\begin{array}{l}\text { Yes } \\
\text { Yes } \\
\text { Yes } \\
\text { Yes }\end{array}$ & $\begin{array}{l}85(4.5) \\
67(3.6) \\
236(12.6) \\
131(7.0)\end{array}$ & $\begin{array}{l}9(5.5) \\
10(6.1) \\
12(7.3) \\
8(4.9)\end{array}$ & $\begin{array}{l}38(3.1) \\
30(2.5) \\
140(11.4) \\
81(6.6)\end{array}$ & $\begin{array}{l}25(6.8) \\
18(4.9) \\
56(15.3) \\
33(9.0)\end{array}$ & $\begin{array}{l}13(10.8) \\
9(7.5) \\
28(23.3) \\
9(7.5)\end{array}$ \\
\hline
\end{tabular}

Abbreviations: HTN, hypertension; DM, diabetes mellitus.

MPR was significantly higher in the switch group (32.8 $\pm 22.7 \%$ ), compared with daily (21.9 $\pm 25.9 \%$ ), weekly ( 22.7 $\pm 27.3 \%$ ), or monthly $(23.2 \pm 27.7 \%)$ patterns; and the latter three groups (daily, weekly, monthly) did not differ significantly in terms of MPR (Figure 2). The length of follow-up period was $5.7 \pm 2.5$ years (range $=1.8-8.6$, median $=6.0$ ) in daily, $5.7 \pm 2.3$ years $(1.7-9.3,6.8)$ in weekly, $5.5 \pm 2.5$ years $(1.8-9.4,6.0)$ in monthly, and $5.5 \pm 2.2$ years $(2.3-9.9,5.0)$ in switch group, respectively. The four groups did not differ significantly in terms of the follow-up period $(P=0.126$ $-0.987)$.

Mean age at initial diagnosis of osteoporosis was $67.1 \pm 9.9$ years. Mean MPR was $26.6 \pm 29.4 \%$ for patients

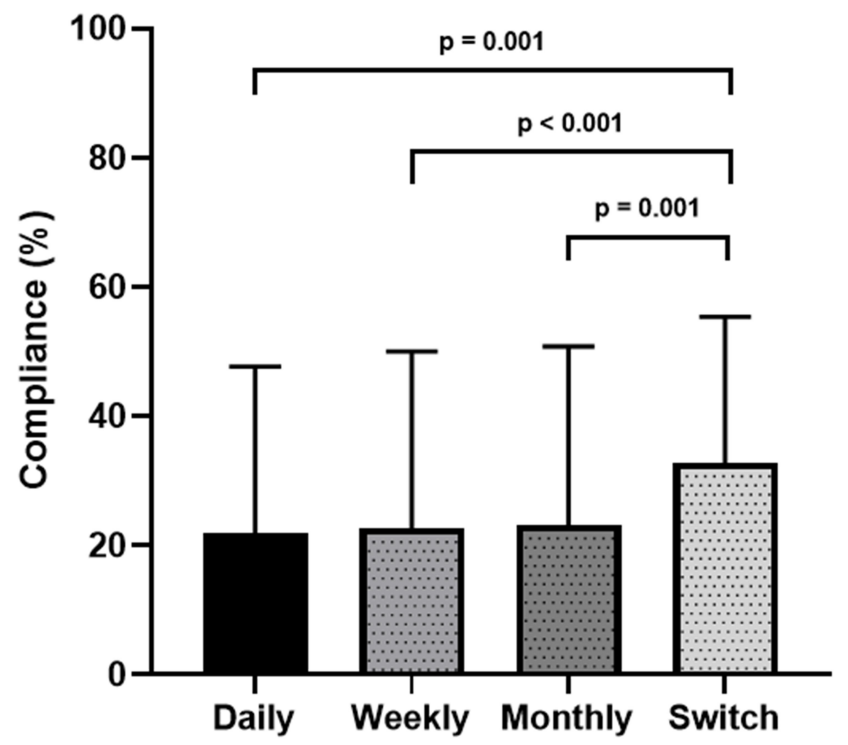

Figure 2 Compliance (medication possession ratio) according to dosing pattern (daily, weekly, monthly, and switch groups). in their 50s, significantly surpassing values of those in their $60 \mathrm{~s} \quad(23.0 \pm 26.0 \% ; \quad P=0.031), 70 \mathrm{~s} \quad(22.1 \pm 26.0 \%$; $P=0.008)$, or $80 \mathrm{~s}$ and beyond $(20.3 \pm 26.8 \% ; P=0.005)$ (Figure 3).

In comparing MPRs of various patient subgroups, including men $(n=324)$ vs women $(n=1549)$, fracture history $(\mathrm{n}=85)$ vs none $(\mathrm{n}=1788)$, surgical history $(\mathrm{n}=67)$ vs none $(\mathrm{n}=1806)$, hypertension $(\mathrm{n}=236)$ vs none $(n=1637)$, and diabetes mellitus $(n=131)$ vs none $(\mathrm{n}=1742)$, only men $(19.8 \pm 26.0 \%)$ and women $(24.1$ $\pm 27.2 \%)$ differed significantly $(P=0.008)$, women leading men in compliance. No other outcomes reached statistical significance (Figure 4).

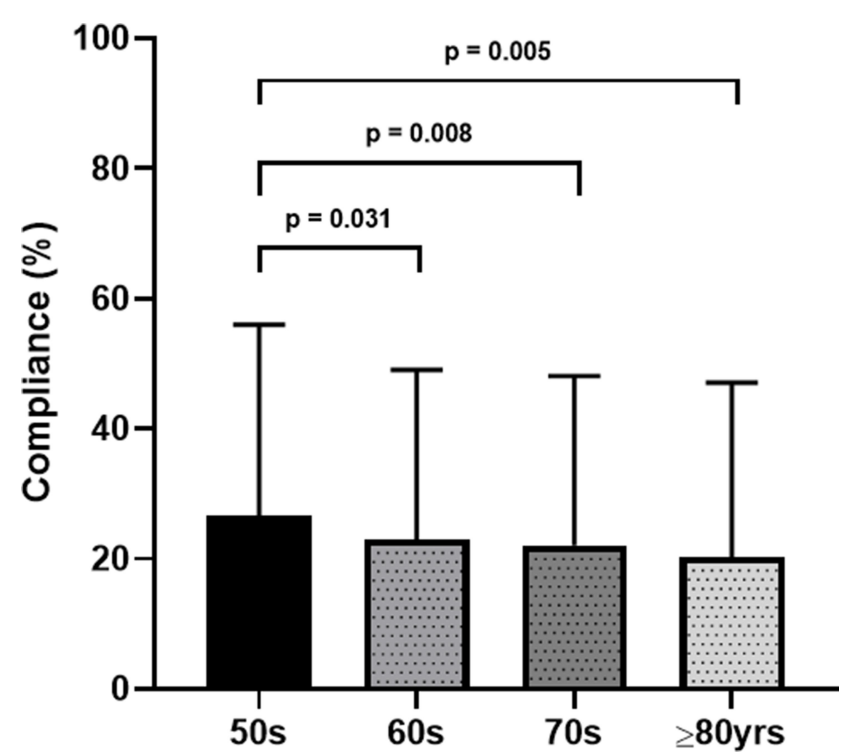

Figure 3 Compliance (medication possession ratio) according to patient age. 

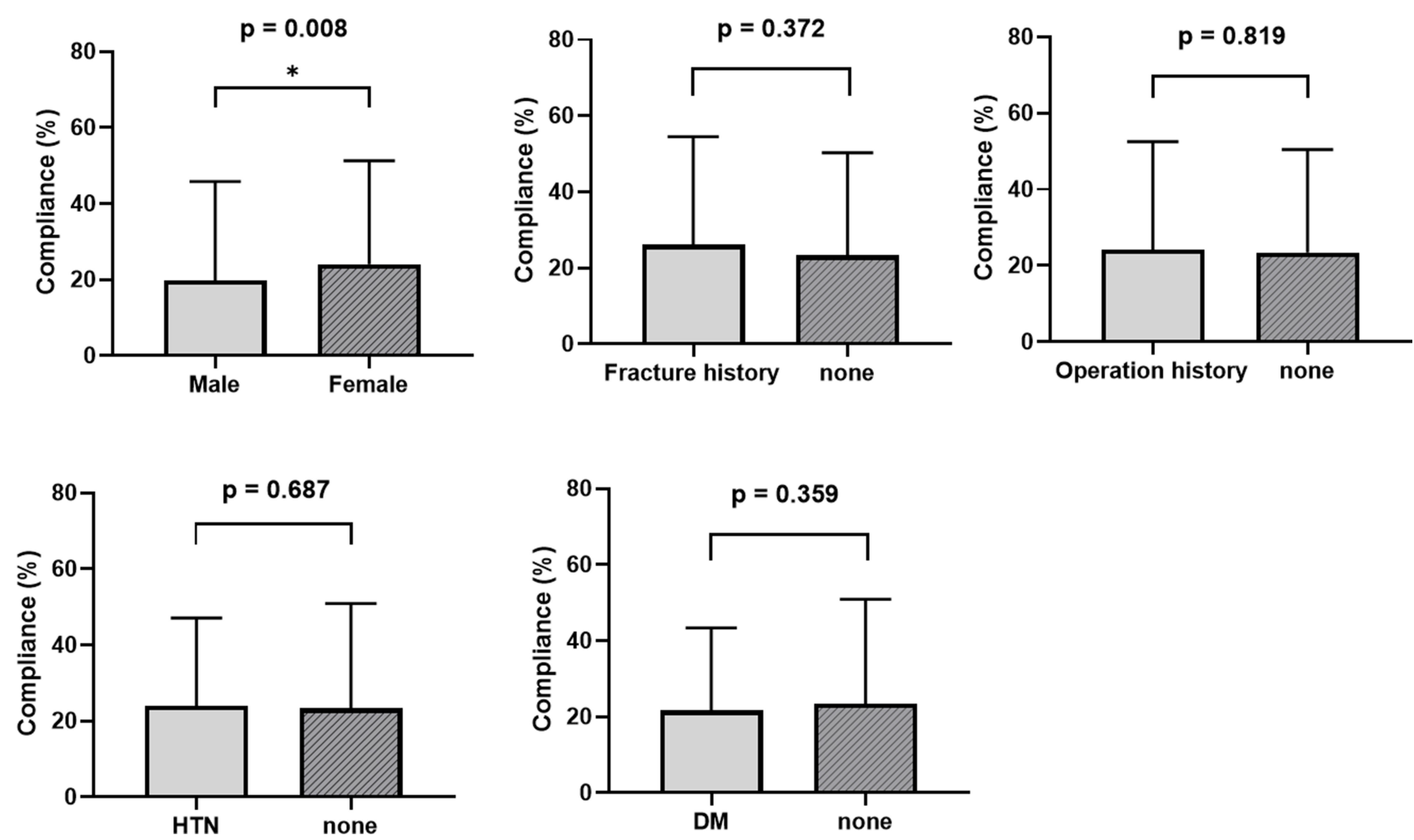

Figure 4 Compliance (medication possession ratios) within opposing patient subgroups (sex, fracture history, surgical history, HTN, and DM). *Statistically significant. Abbreviations: HTN, hypertension; DM, diabetes mellitus.

\section{Multiple Regression Analysis}

As above, younger age, female sex, and switching of prescription pattern emerged as variables significantly associated with better compliance (ie, higher MPR). Multiple regression analysis was then performed to gauge the impact of these three elements on MPR, adjusting for other factors including the length of follow-up period. With MPR as a dependent continuous variable, younger age $(P<0.001)$, female sex $(P=0.004)$, and switching of prescription pattern were all associated with higher MPR. Both decreasing and increasing frequencies were related to higher MPR ( $P=0.013$ and 0.005 , respectively). The length of follow-up period was negatively and significantly associated with the MPR $(P<0.001)$. Details are provided in Table 2.

\section{Discussion}

We evaluated oral bisphosphonate compliance in patients with osteoporosis, focusing on fixed and fluctuating dosing intervals. The chief discovery was that non-static prescription patterns were related to better therapeutic compliance. Although patient age and sex were also significant influences, coexisting chronic diseases (hypertension, diabetes), past osteoporotic fractures, and surgeries related to such fractures were not. Treatment compliance is critical in preventing osteoporotic fractures. A number of earlier studies have underscored the relation between poor compliance and unfavorable clinical outcomes. ${ }^{14,19,32,33}$ Research efforts aimed at improved compliance must therefore be intensified. In addition, it is advisable to take all possible actions to maximize compliance rate. Given this point, it is encouraging that physicianmodified dosing schedules, unlike less malleable parameters (ie, demographics and clinical characteristics), may actually improve compliance.

By analyzing data of the Hungarian National Health Insurance Fund Administration, Lakatos et $\mathrm{al}^{34}$ found greater persistence and compliance with anti-osteoporotic therapies if dosing was less frequent and parenteral in form. Other studies have similarly concluded that broader dosing intervals and injectable formulations increase persistence and compliance, thereby improving clinical outcomes. $^{7,9,35,36}$ In our cohort, MPRs among daily, weekly, and monthly dosing groups $(21.9 \pm 25.9,22.7$ \pm 27.3 , and $23.2 \pm 27.7$, respectively) did not differ significantly. It is notable, however, that switching prescription patterns (decrease or increase dosing frequency) significantly boosted MPR, perhaps by minimizing declines in 
Table 2 Multiple Regression Analysis of Patient Parameters ( $\mathrm{N}=1873)$, Medication Possession Ratio (MPR) as a Dependent Variable

\begin{tabular}{|c|c|c|c|c|c|}
\hline & \multicolumn{2}{|c|}{ Non-Standardized Coefficients } & \multirow{2}{*}{$\begin{array}{l}\text { Standardized Coefficients } \\
\text { Beta }\end{array}$} & \multirow[t]{2}{*}{$\mathbf{t}$} & \multirow[t]{2}{*}{$\mathbf{P}$} \\
\hline & B & Std Error & & & \\
\hline (Constant) & $44.44 I$ & 4.695 & & 9.465 & $<0.001$ \\
\hline Age & -0.289 & 0.065 & -0.106 & -4.473 & $<0.001$ \\
\hline $\operatorname{Sex}^{a}$ & 4.732 & 1.645 & 0.066 & 2.877 & 0.004 \\
\hline Fracture $^{\mathrm{b}}$ & $6.47 I$ & 4.221 & 0.050 & 1.536 & 0.125 \\
\hline Surgery ${ }^{b}$ & -3.354 & 4.702 & -0.023 & -0.713 & 0.476 \\
\hline $\mathrm{HTN}^{\mathrm{b}}$ & 2.240 & 2.020 & 0.027 & 1.109 & 0.268 \\
\hline $\mathrm{DM}^{\mathrm{b}}$ & -1.639 & 2.591 & -0.015 & -0.632 & 0.527 \\
\hline Initial Regimen ${ }^{c}$ & 0.011 & 0.065 & 0.004 & 0.177 & 0.860 \\
\hline Switching ${ }^{\mathrm{b}}$ (Decrease Frequency) & 7.813 & 3.143 & 0.057 & 2.486 & 0.013 \\
\hline Switching ${ }^{\mathrm{b}}$ (Increase Frequency) & 11.773 & 4.207 & 0.065 & 2.798 & 0.005 \\
\hline Follow-Up Period & -1.164 & 0.263 & -0.102 & -4.431 & $<0.001$ \\
\hline
\end{tabular}

Notes: ${ }^{\mathrm{a} C o d e d}$ as Male=0; Female=I. ${ }^{\mathrm{b}}$ Coded as $\mathrm{No}=0$; Yes $=1 .{ }^{\mathrm{c} C o d e d}$ as Daily=I, weekly=7; monthly group $=30$.

Abbreviations: HTN, hypertension; DM, diabetes mellitus.

compliance throughout the study period. In fact, the mean MPR in the switch group was $32.1 \pm 20.5$ before switching prescription pattern and $33.3 \pm 25.6$ after switching, respectively. The two values were not significantly different $(P=0.055)$. The added opportunities to educate patients on new medications and restate the hazards of osteoporosis may likewise have proved beneficial. To be sure, validation of causality was limited by our retrospective design. In our cohort, switching the patterns or not was not randomly assigned, and it was a major limitation of our study. Randomized prospective studies are needed to validate this particular finding.

In another publication, Solomon et al reported female sex and younger as factors associated with increased compliance. ${ }^{15}$ This is aligned with our results, in which female sex and younger age were significantly linked with better compliance. Regarding the effects of sex and age on persistence, Ideguchi et $\mathrm{al}^{37}$ reported significant associations of male sex and older age with low medication persistence. Female patients of younger age are expected to have more serious concerns about osteoporosis, which would have led to a higher rate of compliance. Although we cannot conclude the effects of sex and age considering the complexity of bisphosphonate compliance, ${ }^{18,19}$ patients of male sex or older age may be major target groups aimed to improve compliance and persistence. In addition to older age, the number of comorbidities and number of concomitant medications were associated with worse persistence among women with postmenopausal osteoporosis. ${ }^{18}$ Initially, we had thought that histories of osteoporotic fractures or related surgeries might bolster awareness of bone health, increasing patient compliance. However, such events did nothing to spur compliance and could not be used as therapeutic cudgels. Nevertheless, physicians should not be overconfident about the drug compliance in such patients.

Herein, the MPR (mean=23.4 \pm 27.1 ) served to gauge compliance, falling short of values cited in a previous metaanalysis (range $=54.6-81.3){ }^{32}$ This discrepancy is explainable by our observation period ( $5.7 \pm 2.4$ years), which exceeded those of previous studies. ${ }^{17,-28-30,32}$ Compliance is known to diminish over time, ${ }^{27,38}$ jeopardizing patient outcomes, so developing strategies for long-term compliance is imperative. To adjust the effect of variations in follow-up periods on MPR, the length of follow-up was included in the regression model in Table 2. In fact, it was negatively and significantly associated with the MPR. The relatively low long-term compliance we observed highlights the need for new strategies to ensure compliance. We believe that our finding of switching of prescription patterns is noteworthy considering adjustments for other various factors by using the regression model. Owing to the relatively low MPR and longer period of study, we considered MPR a dependent continuous variable during multiple linear regression analysis, rather than determining its cutpoint.

A national health database ensures access to many subjects, although details are sometimes incomplete. We relied on hospital records, generating fewer subjects but more precise patient profiles and disease characteristics that could be corroborated during telephone interviews. All enrollees with insufficient information were 
individually interviewed by phone after carefully assessing medical records data. Despite their low numbers, the body of information was reliable. The relatively small number of our subjects was still a limitation. Nevertheless, using our number of subjects and their reliable data, we could obtain the statistical significance of our principle finding.

There were other limitations of our study, one being the assumption that MPR is a valid surrogate for proper medication intake; and bias due to various patient health behaviors (not addressed at this time) was a potential concern. It is also quite possible that MPR values derived from prescription claims only (no patient input) were overestimated. Secondly, there might be a chance that the patients had a bisphosphonate drug holiday. However, optimal treatment durations for bisphosphonates remain controversial. Moreover, we did confirm that no subjects discontinued their prescriptions due to the corresponding issue. Lastly, we did not include other anti-osteoporotic drugs. Because bisphosphonates account for $\sim 90 \%$ of antiosteoporotic treatment, ${ }^{39}$ they were the sole consideration.

\section{Conclusion}

In patients prescribed oral bisphosphonates for osteoporosis and followed for an average of 5.7 years, younger age, female sex, and switching of dosing intervals were factors associated with better compliance. It should be emphasized that better compliance was related to change of the prescription pattern, which was modifiable by physicians. Such prescription modifications seem productive and are easily undertaken. Physicians are encouraged to do so in poorly compliant patients requiring long-term treatment.

\section{Ethical Considerations}

The study was carried out in accordance with the ethical principles of the Declaration of Helsinki and approved by the institutional review board at CHA University (No. 2018-10-024-004).

\section{Acknowledgments}

This study was supported by Korea Health Technology R\&D Project through the Korea Health Industry Development Institute, funded by the Ministry of Health \& Welfare, South Korea (No. HI16C1559) and by the National Research Foundation of Korea grant funded by the Korea government (Ministry of Science and ICT) (No. 2019R1C1C1004017).

\section{Disclosure}

The authors (and any members of their family) have no financial affiliation (including research funding) or involvement with any commercial organization that has a direct financial interest in any matter included in this manuscript. The authors have no conflict of interest (ie, personal associations or involvement as a director, officer, or expert witness).

\section{References}

1. Barrett-Connor E, Black D, Bonjour JP, et al. Prevention and management of osteoporosis. WHO Tech Rep Ser. 2003;921:1-164, back cover.

2. Consensus A. Consensus development conference: diagnosis, prophylaxis, and treatment of osteoporosis. Am J Med. 1993;94(6):646-650.

3. Cummings SR, Melton LJ. Epidemiology and outcomes of osteoporotic fractures. Lancet. 2002;359(9319):1761-1767.

4. Scott LJ. Denosumab: a review of its use in postmenopausal women with osteoporosis. Drugs Aging. 2014;31(7):555-576. doi:10.1007/ s40266-014-0191-3

5. Park EJ, Joo IW, Jang MJ, Kim YT, Oh K, Oh HJ. Prevalence of osteoporosis in the Korean population based on Korea National Health and Nutrition Examination Survey (KNHANES), 2008-2011. Yonsei Med J. 2014;55(4):1049-1057. doi:10.3349/ymj.2014.55.4.1049

6. Park SB, Kim J, Jeong JH, et al. Prevalence and incidence of osteoporosis and osteoporotic vertebral fracture in Korea: Nationwide Epidemiological Study focusing on differences in socioeconomic status. Spine. 2016;41(4):328-336.

7. Hadji P, Claus V, Ziller V, Intorcia M, Kostev K, Steinle T. GRAND: the German retrospective cohort analysis on compliance and persistence and the associated risk of fractures in osteoporotic women treated with oral bisphosphonates. Osteoporos Int. 2012;23 (1):223-231. doi:10.1007/s00198-011-1535-z

8. Hoer A, Seidlitz C, Gothe $\mathrm{H}$, et al. Influence on persistence and adherence with oral bisphosphonates on fracture rates in osteoporosis. Patient Prefer Adherence. 2009;3:25-30.

9. Siris ES, Selby PL, Saag KG, Borgstrom F, Herings RM, Silverman SL. Impact of osteoporosis treatment adherence on fracture rates in North America and Europe. Am J Med. 2009;122 (2Suppl):S3-S13. doi:10.1016/j.amjmed.2008.12.002

10. Gold DT, Martin BC, Frytak JR, Amonkar MM, Cosman F. A claims database analysis of persistence with alendronate therapy and fracture risk in post-menopausal women with osteoporosis. Curr Med Res Opin. 2007;23(3):585-594.

11. Cotte FE, Mercier F, De Pouvourville G. Relationship between compliance and persistence with osteoporosis medications and fracture risk in primary health care in France: a retrospective case-control analysis. Clin Ther. 2008;30(12):2410-2422. doi:10.1016/j. clinthera.2008.12.019

12. Majumdar SR, Johnson JA, Lier DA, et al. Persistence, reproducibility, and cost-effectiveness of an intervention to improve the quality of osteoporosis care after a fracture of the wrist: results of a controlled trial. Osteoporos Int. 2007;18(3):261-270. doi:10.1007/ s00198-006-0248-1

13. Caro JJ, Ishak KJ, Huybrechts KF, Raggio G, Naujoks C. The impact of compliance with osteoporosis therapy on fracture rates in actual practice. Osteoporos Int. 2004;15(12):1003-1008. doi:10.1007/ s00198-004-1652-z

14. Siris ES, Harris ST, Rosen CJ, et al. Adherence to bisphosphonate therapy and fracture rates in osteoporotic women: relationship to vertebral and nonvertebral fractures from 2 US claims databases. Mayo Clin Proc. 2006;81(8):1013-1022. doi:10.4065/81.8.1013 
15. Solomon DH, Avorn J, Katz JN, et al. Compliance with osteoporosis medications. Arch Intern Med. 2005;165(20):2414-2419. doi:10.1001/archinte.165.20.2414

16. Silverman SL, Gold DT. Compliance and persistence with osteoporosis therapies. Curr Rheumatol Rep. 2008;10(2):118-122. doi:10.1007/s11926-008-0021-x

17. Karlsson L, Lundkvist J, Psachoulia E, Intorcia M, Strom O. Persistence with denosumab and persistence with oral bisphosphonates for the treatment of postmenopausal osteoporosis: a retrospective, observational study, and a meta-analysis. Osteoporos Int. 2015;26 (10):2401-2411. doi:10.1007/s00198-015-3253-4

18. Cramer JA, Amonkar MM, Hebborn A, Altman R. Compliance and persistence with bisphosphonate dosing regimens among women with postmenopausal osteoporosis. Curr Med Res Opin. 2005;21 (9):1453-1460. doi:10.1185/030079905X61875

19. Huybrechts KF, Ishak KJ, Caro JJ. Assessment of compliance with osteoporosis treatment and its consequences in a managed care population. Bone. 2006;38(6):922-928. doi:10.1016/j.bone.2005.10.022

20. Cosman F, de Beur SJ, LeBoff MS, et al. Clinician's guide to prevention and treatment of osteoporosis. Osteoporos Int. 2014;25 (10):2359-2381. doi:10.1007/s00198-014-2794-2

21. Black DM, Cummings SR, Karpf DB, et al. Randomised trial of effect of alendronate on risk of fracture in women with existing vertebral fractures. Fracture Intervention Trial Research Group. Lancet. 1996;348(9041):1535-1541. doi:10.1016/S0140-6736(96)07088-2

22. Papapoulos SE. Use of bisphosphonates in the management of postmenopausal osteoporosis. Ann N Y Acad Sci. 2011;1218:15-32. doi:10.1111/j.1749-6632.2010.05767.x

23. Rabenda V, Hiligsmann M, Reginster JY. Poor adherence to oral bisphosphonate treatment and its consequences: a review of the evidence. Expert Opin Pharmacother. 2009;10(14):2303-2315. doi:10.1517/14656560903140533

24. Cramer JA, Gold DT, Silverman SL, Lewiecki EM. A systematic review of persistence and compliance with bisphosphonates for osteoporosis. Osteoporos Int. 2007;18(8):1023-1031. doi:10.1007/ s00198-006-0322-8

25. Briesacher BA, Andrade SE, Harrold LR, Fouayzi H, Yood RA. Adoption of once-monthly oral bisphosphonates and the impact on adherence. Am J Med. 2010;123(3):275-280. doi:10.1016/j. amjmed.2009.05.017

26. Cramer JA, Silverman SL, Gold DT. Methodological considerations in using claims databases to evaluate persistence with bisphosphonates for osteoporosis. Curr Med Res Opin. 2007;23(10):2369-2377. doi:10.1185/030079907X226311

27. Li L, Roddam A, Ferguson S, Feudjo-Tepie M, Taylor A, Jick S. Switch patterns of osteoporosis medication and its impact on persistence among postmenopausal women in the U.K. General Practice Research Database. Menopause. 2014;21(10):1106-1113. doi:10.1097/GME.000 0000000000214
28. Cheng LI, Durden E, Limone B, et al. Persistance and compliance with osteroporosis therapies among women in a commercially insured population in the United States. J Manag Care Spec Pharm. 2015;21(9):824-833, 833a. doi:10.18553/jmcp.2015.21.9.824

29. Cotte FE, Fardellone P, Mercier F, Gaudin AF, Roux C. Adherence to monthly and weekly oral bisphosphonates in women with osteoporosis. Osteoporos Int. 2010;21(1):145-155.

30. Weycker D, Macarios D, Edelsberg J, Oster G. Compliance with drug therapy for postmenopausal osteoporosis. Osteoporos Int. 2006;17 (11):1645-1652. doi:10.1007/s00198-006-0179-x

31. Andrade SE, Kahler KH, Frech F, Chan KA. Methods for evaluation of medication adherence and persistence using automated databases. Pharmacoepidemiol Drug Saf. 2006;15(8):565-574;discussion 575-567. doi:10.1002/pds. 1230

32. Imaz I, Zegarra P, Gonzalez-Enriquez J, Rubio B, Alcazar R, Amate JM. Poor bisphosphonate adherence for treatment of osteoporosis increases fracture risk: systematic review and meta-analysis. Osteoporos Int. 2010;21(11):1943-1951. doi:10.1007/s00198-0091134-4

33. Penning-van Beest FJ, Erkens JA, Olson M, Herings RM. Loss of treatment benefit due to low compliance with bisphosphonate therapy. Osteoporos Int. 2008;19(4):511-517. doi:10.1007/s00198007-0466-1

34. Lakatos P, Takacs I, Marton I, et al. A retrospective longitudinal database study of persistence and compliance with treatment of osteoporosis in Hungary. Calcif Tissue Int. 2016;98(3):215-225. doi:10.1007/s00223-015-0082-6

35. Hadji P, Papaioannou N, Gielen E, et al. Persistence, adherence, and medication-taking behavior in women with postmenopausal osteoporosis receiving denosumab in routine practice in Germany, Austria, Greece, and Belgium: 12-month results from a European non-interventional study. Osteoporos Int. 2015;26(10):2479-2489. doi:10.1007/s00198-015-3164-4

36. Silverman SL, Siris E, Kendler DL, et al. Persistence at 12 months with denosumab in postmenopausal women with osteoporosis: interim results from a prospective observational study. Osteoporos Int. 2015;26(1):361-372. doi:10.1007/s00198-014-2871-6

37. Ideguchi H, Ohno S, Hattori H, Ishigatsubo Y. Persistence with bisphosphonate therapy including treatment courses with multiple sequential bisphosphonates in the real world. Osteoporos Int. 2007;18(10):1421-1427. doi:10.1007/s00198-007-0406-0

38. Iolascon G, Gimigliano F, Orlando V, Capaldo A, Di Somma C, Menditto E. Osteoporosis drugs in real-world clinical practice: an analysis of persistence. Aging Clin Exp Res. 2013;25(Suppl 1):S137S141. doi:10.1007/s40520-013-0127-5

39. Cho H, Byun JH, Song I, et al. Effect of improved medication adherence on health care costs in osteoporosis patients. Medicine. 2018;97(30):e11470. doi:10.1097/MD.0000000000011470
Patient Preference and Adherence

\section{Publish your work in this journal}

Patient Preference and Adherence is an international, peer-reviewed, open access journal that focusing on the growing importance of patient preference and adherence throughout the therapeutic continuum. Patient satisfaction, acceptability, quality of life, compliance, persistence and their role in developing new therapeutic modalities and compounds to optimize clinical outcomes for existing disease states are major areas of interest for the journal. This journal has been accepted for indexing on PubMed Central. The manuscript management system is completely online and includes a very quick and fair peer-review system, which is all easy to use. Visit http:// www.dovepress.com/testimonials.php to read real quotes from published authors. 